DOI: https://doi.org/10.15688/jvolsu3.2017.3.5

UDC 332.053

LBC 65.050

\title{
DYNAMIC EFFECTS OF THE "SHOCKS" INFLUENCE ON THE ECONOMIC SAFETY OF MACROREGIONS
}

\author{
Lidiya S. Guryanova \\ Simon Kuznets Kharkiv National University of Economics, Kharkiv, Ukraine \\ Tamara S. Klebanova \\ Simon Kuznets Kharkiv National University of Economics, Kharkiv, Ukraine \\ Sergey A. Razumovskiy \\ Simon Kuznets Kharkiv National University of Economics, Kharkiv, Ukraine \\ Vyacheslav V. Nepomnyashchiy \\ Simon Kuznets Kharkiv National University of Economics, Kharkiv, Ukraine
}

\begin{abstract}
Modern forms of integration processes, along with a number of opportunities to obtain synergistic effects by regions, impose additional threats and risks. In particular, such risks include deterioration of trading conditions in partner countries, depreciation of assets, unidirectional reaction to "shocks". The need to monitor and prevent such specific risks and threats requires an appropriate transformation of economic security systems (RESS) of the regions (macroregions). The development of a model basis is one of the ways to increase the RESS functioning efficiency. The basis would allow to analyze dynamic effects of the "shocks" influence; to identify the system components, which at certain stages contribute to an increase in the overall level of economic safety, or, on the contrary, create additional threats. The authors propose a methodical approach to the formation of such a model basis, which is based on the application of principal components method, canonical correlations method, the method of development level, vector autoregressive technologies, vector models of error correction. The proposed methodical approach is implemented on the data of macroregions' financial security indicators, as one of the dominant components of economic security. The obtained results allowed to reveal the interrelations between the structural components of safety, taking into account long-term relationships, short-term effects and the speed of return to the equilibrium trajectory after the impact of external "shocks" (threats). The developed models of dynamically stable systems have shown that in modern conditions there is a high probability of short-term local crises formation, since the reaction at the time of the "shock" impact often has the character of "explosive" oscillations. The study of dynamically unstable systems models has made it possible to determine the points of bifurcation, the dominant threats, the elimination of which would stabilize the situation. Security subsystems, which are the most sensitive to the impact of external "shocks" and the priority channels for the transmission of external stresses / infections were identified. The developed complex of models can be considered as an element of the RESS forecasting and analytical mechanism model basis.
\end{abstract}

Key words: macroregion, security, stochastic "shock", dynamic effects, modeling, estimation.

УДК 332.053

ББК 65.050

\section{АНАЛИЗ ДИНАМИЧЕСКИХ ЭФФЕКТОВ ВЛИЯНИЯ «ШОКОВ» НА ЭКОНОМИЧЕСКУЮ БЕЗОПАСНОСТЬ МАКРОРЕГИОНОВ}

\author{
Лидия Семеновна Гурьянова \\ Харьковский национальный экономический университет им. С. Кузнеца, г. Харьков, Украина
}


Анализ динамических эффектов влияния «шоков» на экономическую безопасность макрорегионов

Тамара Семеновна Клебанова

Харьковский национальный экономический университет им. С. Кузнеца, г. Харьков, Украина

\section{Сергей Александрович Разумовский}

Харьковский национальный экономический университет им. С. Кузнеца, г. Харьков, Украина

\section{Вячеслав Владимирович Непомнящий}

Харьковский национальный экономический университет им. С. Кузнеца, г. Харьков, Украина

Аннотация. Современные формы интеграционных процессов наряду с целым рядом возможностей получения синергетических эффектов регионами несут в себе дополнительные угрозы и риски. В частности, к таким рискам относятся: ухудшение торговых условий в странах-партнерах, обесценивание активов, однонаправленная реакция на «шоки». Необходимость мониторинга и предупреждения таких специфических рисков и угроз требует соответствующей трансформации систем экономической безопасности регионов (макрорегионов) (СЭБР). Направлением повышения эффективности функционирования СЭБР является разработка модельного базиса, позволяющего провести анализ динамических эффектов влияния «шоков»; выявить компоненты системы, которые на определенных этапах способствуют повышению общего уровня экономической безопасности либо, наоборот, создают дополнительные угрозы. В работе предложен методический подход к формированию подобного модельного базиса, который основан на применении метода главных компонент, канонических корреляций, метода уровня развития, векторных авторегрессионных технологий, векторных моделей коррекции ошибки. Предложенный методический подход реализован на данных индикаторов финансовой безопасности макрорегионов как одной из доминантных составляющих экономической безопасности. Полученные результаты позволили выявить взаимосвязи между структурными составляющими безопасности, учесть долгосрочные соотношения, краткосрочные эффекты и скорость возврата к равновесной траектории после воздействия внешних «шоков» (угроз). Разработанный комплекс моделей может рассматриваться как элемент модельного базиса прогнозно-аналитического механизма СЭБР.

Ключевые слова: макрорегион, безопасность, стохастический «шок», динамические эффекты, моделирование, оценка.

\section{Введение}

Актуальность исследования экономической безопасности регионов (макрорегионов, стран) в современных условиях обусловлена тем, что широкомасштабные международные интеграционные процессы, наряду с привлечением иностранного капитала, повышением трудовой мобильности и т. д., несут в себе дополнительные угрозы и риски. В частности, к таким рискам относятся: ухудшение торговых условий в странах-партнерах, обесценивание активов, однонаправленная реакция на «шоки» и эффект «эпидемии». Необходимость мониторинга и предупреждения таких специфических рисков и угроз требует трансформации систем экономической безопасности регионов (СЭБР).

Направлением повышения эффективности функционирования СЭБР является разработка модельного базиса, позволяющего осуществить раннее обнаружение угроз, связанных с различными каналами инфицирования кризисом, и предупредить или смягчить по- следствия их воздействия. Следует отметить, что проблеме моделирования СЭБР посвящены работы таких авторов, как В. Геец, Т. Клебанова, К. Ковальчук, Ю. Лысенко, Р. Нижегородцев, А. Черняк и др. Так, в работах В. Гееца, Т. Клебановой, Р. Нижегородцева [7; 8] рассматриваются вопросы обоснования системы диагностических индикаторов экономической безопасности региона, оценки уровня угроз, идентификации класса угроз, прогнозирования уровня экономической безопасности с помощью методов многомерного анализа, VAR-, ECM-моделей, фильтра Калмана, метода «Гусеница», когнитивного моделирования. Исследования А. Черняка, В. Хомяка [10] посвящены моделированию валютной безопасности как составляющей экономической безопасности макрорегиона, прогнозированию кризиса платежного баланса, выбору механизмов его предупреждения. В работе К. Ковальчука, С. Маринчука [6] рассматривается проблема разработки модельного базиса выбора оффшорных зон для налоговой оптимиза- 
ции, затронута задача формирования эффективных «внутренних» зон налоговой лояльности. Статья Г. Великоиваненко, И. Мирошниченко затрагивает вопросы моделирования инвестиционного потенциала, уровня инвестиционной безопасности как базовой составляющей экономической безопасности региона (ЭБР) [2]. Различные аспекты моделирования производственно-фискальных эффектов обеспечения экономической безопасности рассмотрены в работах Л. Гурьяновой, Л. Чаговец [5; 9]. Следует отметить, что, несмотря на безусловную эффективность предлагаемых авторами подходов, существующие разработки касаются локальных задач оценки, прогнозирования уровня безопасности, оценки уровня угроз, последствий их пролонгированного воздействия. Слабо затронута проблема реализации системного подхода, позволяющего провести анализ взаимосвязи основных элементов системы; выявить компоненты, которые на определенных этапах способствуют повышению общего уровня экономической безопасности либо, наоборот, создают дополнительные угрозы при воздействии внешних «шоков».

Цель работы состоит в формировании комплекса моделей оценки и анализа динамики уровня экономической безопасности региона, который на основе методов многомерного анализа, векторных авторегрессионных технологий, моделей коррекции ошибки позволяет оценить системные динамические эффекты влияния внешних «шоков» (угроз); выделить компоненты системы, оказывающие компенсационное или дестабилизирующее воздействие при влиянии внешних «шоков». Достижение поставленной цели предполагает решение следующих задач:

- разработка моделей оценки уровня экономической безопасности региона;

- построение моделей прогнозирования уровня экономической безопасности региона;

- формирование и анализ сценариев импульсных реакций СЭБР на воздействие внешних «шоков».

Научная новизна результата заключается в том, что предлагается методический подход к разработке модельного базиса оценки и анализа динамики уровня ЭБР, который на основе методов факторного анализа, канонических корреляций, метода уровня развития,
VAR-, ECM-моделей позволяет провести анализ динамических эффектов влияния внешних «шоков» (угроз) на функциональные составляющие и систему в целом, оценить стабильность системы. Разработанный комплекс моделей может рассматриваться как элемент модельного базиса прогнозно-аналитического механизма СЭБР.

\section{Методика исследования}

Предлагаемый в работе методический подход включает следующие основные этапы:

Этаn 1. Обоснование системы индикаторов экономической безопасности региона на основе методов многомерного анализа.

С системных позиций экономическая безопасность (ЭБ) представляет собой сложную многоуровневую структуру, для которой характерно наличие множества элементов, большого числа разнообразных связей, циркуляция больших потоков информации, определяющих ее внутреннюю динамику. Таким образом, экономическая безопасность характеризуется высокой степенью сложности и многоаспектностью, и, как следствие, информационная модель ЭБ должна включать большое число количественных и качественных показателей. Вместе с этим учет значительного числа показателей приводит к информационной перегруженности процессов принятия решений. В результате возникает задача формирования системы наиболее информативных, диагностических показателей, позволяющих снизить размерность исходного информационного пространства признаков без потери значимой информации. Для решения этой задачи в экономической литературе используются две группы методов: методы, основанные на критериях автоинформативности; методы, ориентированные на оценку информативности на основе анализа причинно-следственных связей (внешней информативности) [1]. Первая группа методов позволяет оценить информационную значимость показателей, выявить скрытые свойства и закономерности в больших объемах необработанных данных, в том случае когда неизвестна структура входного и выходного множества данных. Преимуществом второй группы методов является возможность снижения размерности информаци- 
онного пространства признаков на основе анализа причинно-следственных связей множества входных и выходных индикаторов. Выбор метода обусловливается полным или неполным обеспечением информацией, объемом выборки, структурой множества входных и выходных индикаторов, наличием обучающей выборки. С учетом ограничений на тип данных, структуру групп показателей разработана блок-схема формирования системы диагностических показателей экономической безопасности, подробное описание которой приведено в работах Л.С. Гурьяновой, В.В. Непомнящего [3; 5]. Предложенный подход основан на синтезе методов главных компонент и канонического анализа. Выбор метода главных компонент объясняется возможностью формирования системы обобщенных латентных факторов, выбора наиболее значимых индикаторов. Метод канонических корреляций дает возможность анализировать взаимосвязь нескольких выходных показателей и большого числа факторов. Данное свойство является важным при обосновании показателей в системе управления безопасностью, поскольку динамика подсистем экономической безопасности характеризуется большим набором признаков. Выбор одного наиболее значимого индикатора будет приводить к искажению результатов оценки.

Этап 2. Комплексная оценка уровня экономической безопасности и ее структурных составляющих. Построение системы комплексных (по всей системе показателей) и локальных (по отдельным компонентам) интегральных оценок уровня экономической безопасности обусловлено разновекторностью изменения показателей, что усложняет их анализ и требует представления в виде синтетической оценки, которая является результатом свертки индикаторов, отражающих развитие отдельных подсистем ЭБ. Блок-схема формирования интегральной оценки уровня ЭБ основана на одном из методов построения эталонного объекта - таксономическом показателе уровня развития, подробное описание которого дано в монографии «Адаптивные методы в системах принятия решений» [1]. Выбор метода обусловлен такими его преимуществами: отсутствие ограничений на характер информационного пространства признаков (могут быть включены показатели, положи- тельная динамика которых свидетельствует как о снижении, так и о росте уровня экономической безопасности); исходная система показателей может содержать признаки, которые имеют разную размерность; значения интегрального показателя имеют нормированный диапазон изменения, что обеспечивает интерпретируемость полученных результатов.

Эman 3. Разработка моделей динамики уровня экономической безопасности. Моделирование динамики системы экономической безопасности осуществляется на основе VAR- и ECM-моделей [7]. Выбор этого инструментария обусловлен возможностью моделировать взаимосвязанные экономические переменные; исследовать долгосрочную взаимосвязь, отклонения от равновесного состояния; оценивать влияние «шоков» на динамику индикаторов экономической безопасности. Проведение коинтеграционного анализа предполагает: проверку временных рядов на стационарность с помощью критерия Дики - Фуллера; определение порядка интеграции; проверку на коинтеграцию; построение ECM- или VAR-модели; импульсный анализ и декомпозицию дисперсий. Импульсный анализ (анализ реагирования на «шоки») позволяет осуществлять динамическую имитацию внешнего «шока» в отношении каждой из эндогенных переменных, а затем провести оценку реакции системы на этот импульс. Функция импульсных реакций показывает изменение эндогенных показателей в ответ на «шок» (изменение одного из возмущений системы). Декомпозиция дисперсий ошибок прогноза дает возможность проанализировать влияние различных шоков на дисперсию ошибки прогнозов для разных периодов упреждения. Иными словами, декомпозиция дисперсий показывает пропорции дисперсии, вызванные «шоками» различных переменных. Более подробно описание блоксхемы анализа динамики экономических индикаторов с использованием VAR- и ECM-моделей приведено в работе Л.С. Гурьяновой, С.В. Прокопович, Т.Н. Труновой [4].

Следует отметить, что предложенный методический подход является достаточно универсальным и может быть использован для анализа динамики индикаторов безопасности систем разного уровня иерархии (макро-, мезоуровня) и функционального назначения (финансовой, технико-производственной и т. д.). 


\section{МЕЖДУНАРОДНЫЕ ИНТЕГРАЦИОННЫЕ ПРОЦЕССЫ}

\section{Результаты исследования}

Предложенный методический подход реализован на данных индикаторов финансовой безопасности макрорегионов как одной из доминантных составляющих экономической безопасности. Разработанный комплекс моделей включает следующие основные модули: 1) модуль моделей анализа индикаторов финансовой безопасности динамически стабильных систем (на примере стран Евросоюза); 2) модуль моделей анализа индикаторов финансовой безопасности динамически нестабильных систем (на примере Украины); 3) модуль моделей анализа индикаторов безопасности с учетом возможных каналов 〈инфицирования кризисом». В качестве информационной базы исследования рассматривались статистические данные индикаторов финансовой безопасности стран Евросоюза и Украины по таким направлениям оценки, как бюджетная безопасность, безопасность денежного рынка, валютная безопасность, долговая безопасность, безопасность страхового рынка, безопасность фондового рынка, безопасность банковской системы, инвестиционная безопасность, - за последние восемь лет в помесячном разрезе. Выбор периода анализа обусловлен мето- дологической преемственностью и информационной обеспеченностью системы индикаторов. Расчеты проводились с помощью ППП «Statistica», «EViews». Ниже приведено описание основных результатов.

Реализация первых двух этапов приведенного выше методического подхода позволила получить систему интегральных показателей уровня финансовой безопасности стран Евросоюза и Украины. Динамика обобщенного (по всей системе показателей) и локальных (по отдельным компонентам финансовой безопасности) интегральных показателей для стран Евросоюза отоброжена на рисунке 1.

Анализ данных, приведенных на рисунке 1, позволяет сделать вывод об устойчивых положительных тенденциях изменения уровня страховой, банковской, фондовой и инвестиционной безопасности стан Еврозоны. Негативные тенденции характерны для валютной, долговой, монетарной, бюджетной безопасности. Для уровня финансовой безопасности в целом наблюдается позитивная динамика изменения. Однако значение интегрального показателя уровня финансовой безопасности на конец анализируемого периода, равное 0,38 , свидетельствует о существенном уровне угроз.

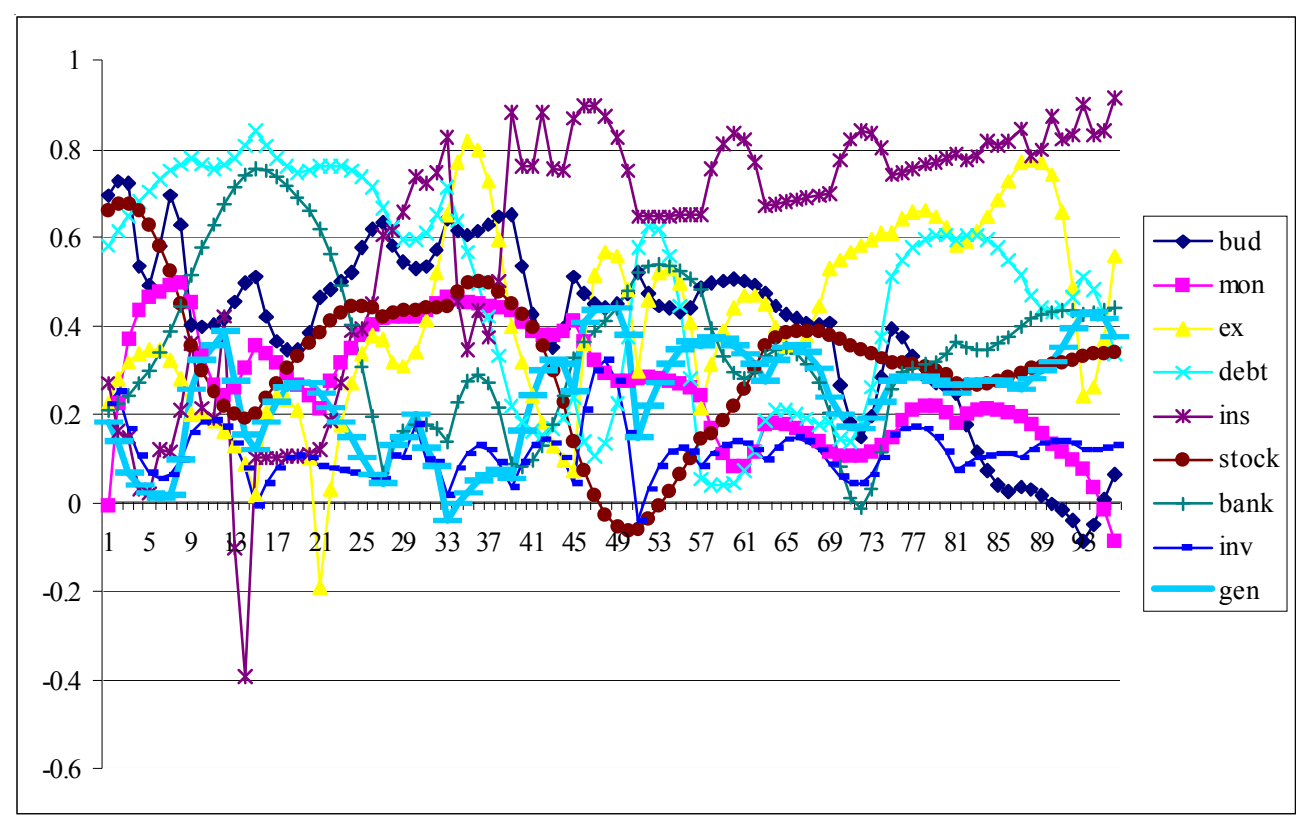

Рис. 1. Динамика интегральных показателей финансовой безопасности стран Еврозоны:

bud - бюджетная безопасность; mon - безопасность денежного рынка; еx - валютная безопасность; $d e b t$ - долговая безопасность; ins - безопасность страхового рынка; stock - безопасность фондового рынка; bank - безопасность банковской системы; inv - инвестиционная безопасность; gen - финансовая безопасность

Примечание. Составлено на основе авторских расчетов. 
Анализ динамических эффектов влияния «шоков» на экономическую безопасность макрорегионов

Для анализа влияния «шоков» на динамику индикаторов финансовой безопасности стран ЕС осуществлялось построение векторной авторегрессионной модели (этап 3 методического подхода). Тестирование временных рядов на стационарность проводилось с помощью ADFтеста. Результаты представлены в таблице 1.

Как видно из таблицы 1, временные ряды интегральных показателей банковской, долговой, валютной, инвестиционной безопасности являются стационарными в уровнях. Для ос- тальных индикаторов осуществлялся переход к первым разностям.

Тестирование направленности причинноследственных связей 36 пар переменных проводилось на основе теста Гренджера. Фрагмент результатов теста приведен на рисунке 2 .

Данные, представленные на рисунке 2, подтверждают гипотезу о наличии двухсторонних причинно-следственных связей между уровнем фондовой и долговой безопасности, валютной и финансовой безопасности, фондовой и страховой

Таблица 1

Тестирование временных рядов на стационарность с помощью ADF-теста

\begin{tabular}{|c|c|c|c|c|c|}
\hline \multirow[t]{2}{*}{$\begin{array}{l}\text { Условное обозначе- } \\
\text { ние переменой }\end{array}$} & \multirow{2}{*}{$\begin{array}{c}\text { Расчетное } \\
\text { значение } \\
\text { ADF-статистики }\end{array}$} & \multicolumn{3}{|c|}{$\begin{array}{c}\text { Критическое значение статистики } \\
\text { МакКинона }\end{array}$} & \multirow{2}{*}{ Выводы } \\
\hline & & $1 \%$ & $5 \%$ & $10 \%$ & \\
\hline BANK & -3.332595 & \multirow{14}{*}{-3.501445} & \multirow{14}{*}{-2.892536} & \multirow{14}{*}{-2.583371} & $\begin{array}{l}\text { Ряд стационарный с вероятно- } \\
\text { стью } 95 \%\end{array}$ \\
\hline BUD & -1.210774 & & & & Ряд нестационарный \\
\hline $\mathrm{D}(\mathrm{BUD})(\mathrm{d}=1)$ & -8.268471 & & & & $\begin{array}{l}\text { Ряд стационарный с вероятно- } \\
\text { стью } 99 \%\end{array}$ \\
\hline DEBT & -2.942652 & & & & $\begin{array}{l}\text { Ряд стационарный с вероятно- } \\
\text { стью } 95 \%\end{array}$ \\
\hline $\mathrm{EX}$ & -3.333005 & & & & $\begin{array}{l}\text { Ряд стационарный с вероятно- } \\
\text { стью } 95 \%\end{array}$ \\
\hline GEN & -2.017354 & & & & Ряд нестационарный \\
\hline $\mathrm{D}(\mathrm{GEN})(\mathrm{d}=1)$ & -4.761836 & & & & $\begin{array}{l}\text { Ряд стационарный с вероятно- } \\
\text { стью } 99 \%\end{array}$ \\
\hline INS & -1.716980 & & & & Ряд нестационарный \\
\hline $\mathrm{D}(\mathrm{INS})(\mathrm{d}=1)$ & -6.420055 & & & & $\begin{array}{l}\text { Ряд стационарный с вероятно- } \\
\text { стью } 99 \% \\
\end{array}$ \\
\hline $\mathrm{INV}$ & -4.679311 & & & & $\begin{array}{l}\text { Ряд стационарный с вероятно- } \\
\text { стью } 99 \%\end{array}$ \\
\hline MON & -0.692990 & & & & Ряд нестационарный \\
\hline $\mathrm{D}(\mathrm{MON})(\mathrm{d}=1)$ & -6.112416 & & & & $\begin{array}{l}\text { Ряд стационарный с вероятно- } \\
\text { стью } 99 \%\end{array}$ \\
\hline STOCK & -1.904160 & & & & Ряд нестационарный \\
\hline $\mathrm{D}(\mathrm{STOCK})(\mathrm{d}=1)$ & -4.222467 & & & & $\begin{array}{l}\text { Ряд стационарный с вероятно- } \\
\text { стью } 99 \%\end{array}$ \\
\hline
\end{tabular}

Примечание. Составлено авторами.

\begin{tabular}{|c|c|c|c|}
\hline Null Hypothesis: & Obs & F-Statistic & Prob. \\
\hline STOCK does not Granger Cause DEBT & 89 & 1.80305 & 0.0993 \\
\hline DEBT does not Granger Cause STOCK & & 2.46712 & 0.0248 \\
\hline GEN does not Granger Cause EX & 89 & 2.91040 & 0.0096 \\
\hline EX does not Granger Cause GEN & & 1.86611 & 0.0874 \\
\hline STOCK does not Granger Cause INS & 89 & 3.77611 & 0.0015 \\
\hline INS does not Granger Cause STOCK & & 1.81029 & 0.0979 \\
\hline
\end{tabular}

Рис. 2. Результаты теста Гренджера (фрагмент)

Примечание. Составлено авторами. 


\section{МЕЖДУНАРОДНЫЕ ИНТЕГРАЦИОННЫЕ ПРОЦЕССЫ}

безопасности с вероятностью 99 \%. Аналогичные результаты получены по остальным переменным. Величина лага при реализации теста и построении векторной авторегрессионной модели определялась на основе информационного критерия Акайка. Значения критерия даны в таблице 2 .

Как видно из таблицы 2, минимальное значение критерия наблюдается для лага 7. Данный лаг был задан экзогенно при построении векторной авторегрессионной модели. Поскольку переменные имеют различный порядок интеграции (см. табл. 1), тест на коинтег- рацию не проводился. Оценивание VAR (7) осуществлялось в среде «EViews».

Сравнение фактических и расчетных данных по некоторым из интегральных показателей составляющих финансовой безопасности дано на рисунке 3.

Анализ данных, приведенных на рисунке 3, дает возможность говорить о достаточно хорошей точности приближения и возможности использования модели для дальнейшего анализа. Критерии качества прогноза представлены в таблице 3.

\section{Значения информационного критерия Акайка}

Таблица 2

\begin{tabular}{|c|c|c|}
\hline Лаг & $\begin{array}{c}\text { Количество значимых } \\
\text { причинно-следственных связей }\end{array}$ & $\begin{array}{c}\text { Критерий } \\
\text { Акайка }\end{array}$ \\
\hline 1 & 16 & $-33,88$ \\
\hline 2 & 16 & $-36,25$ \\
\hline 3 & 19 & $-36,17$ \\
\hline 4 & 14 & $-35,71$ \\
\hline 5 & 19 & $-35,58$ \\
\hline 6 & 16 & $-37,32$ \\
\hline $\mathbf{7}$ & $\mathbf{1 9}$ & $\mathbf{- 4 2 , 5 8}$ \\
\hline 8 & 17 & $-42,03$ \\
\hline
\end{tabular}

Примечание. Составлено авторами.
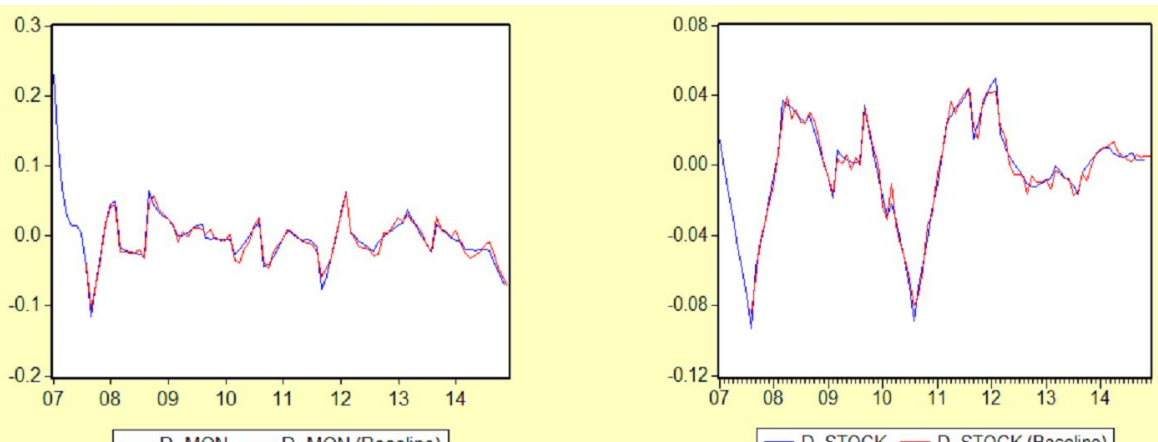

-D_MON -D_MON (Baseline)

-D_STOCK - D_STOCK (Baseline)
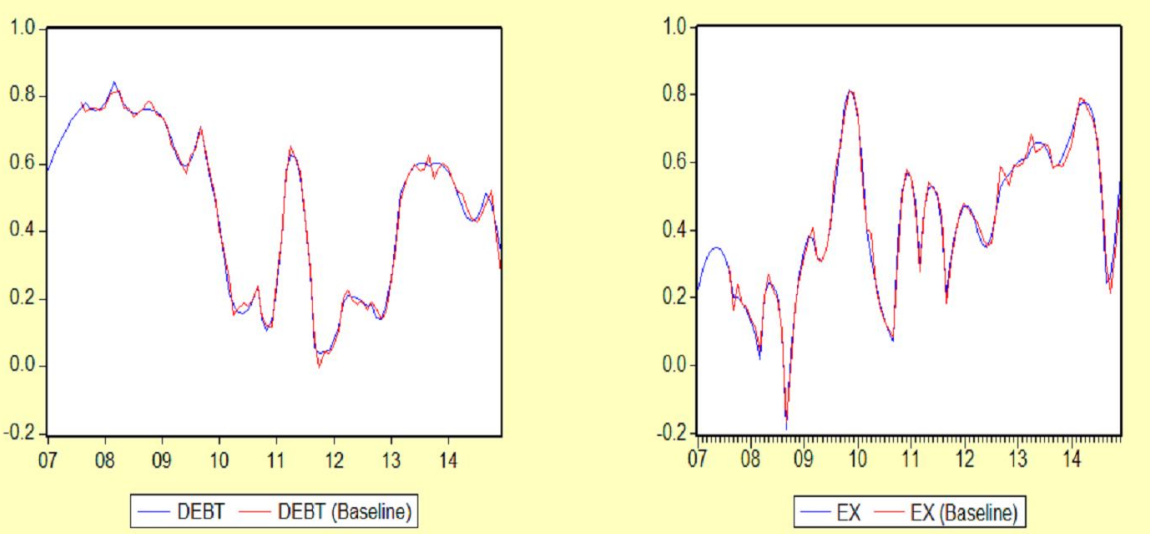

Рис. 3. Фактические и расчетные (модельные) значения индикаторов финансовой безопасности стран ЕС (фрагмент) 
Анализ динамических эффектов влияния «шоков» на экономическую безопасность макрорегионов

Близкие к 0 значения средней ошибки, средней абсолютной ошибки свидетельствуют о хорошей прогностической точности модели. Значения средней абсолютной ошибки аппроксимации для временных рядов интегральных показателей бюджетной, монетарной, валютной, долговой, фондовой, банковс- кой, инвестиционной, финансовой безопасности не превышают $10 \%$. Последнее позволяет сделать вывод о высоком качестве прогноза и возможности применения модели для дальнейшего исследования. Результаты анализа функции импульсных откликов даны на рисунке 4.

Таблица 3

Критерии качества уравнений VAR-модели $(p=7)$

\begin{tabular}{|l|c|c|c|c|c|c|c|c|c|}
\hline $\begin{array}{l}\text { Условное обо- } \\
\text { значение }\end{array}$ & BANK & BUD & D_DEBT & D_EX & GEN & INV & INS & MON & STOCK \\
\hline R-squared & 0.995736 & 0.721364 & 0.912823 & 0.900171 & 0.940949 & 0.976900 & 0.994306 & 0.987824 & 0.985268 \\
\hline Sum sq. resids & 0.012761 & 0.062280 & 0.022276 & 0.123488 & 0.004328 & 0.001693 & 0.029054 & 0.049045 & 0.003964 \\
\hline S.E. equation & 0.023059 & 0.050941 & 0.030466 & 0.071731 & 0.013429 & 0.008400 & 0.034793 & 0.045206 & 0.012851 \\
\hline Akaike AIC & -4.546276 & -2.961027 & -3.989146 & -2.276525 & -5.627546 & -6.565898 & -3.723526 & -3.199928 & -5.715514 \\
\hline Schwarz SC & -2.744576 & -1.159328 & -2.187446 & -0.474826 & -3.825846 & -4.764199 & -1.921826 & -1.398228 & -3.913815 \\
\hline m.e. & -0.00148 & 0.000857 & 0.000539 & 0.000703 & 0.000547 & -0.00089 & 0.000854 & 0.0003754 & 0.0014424 \\
\hline m.a.e. & 0.03342266 & 0.01521557 & 0.01834 & 0.015133 & 0.099421 & 0.008151 & 0.009854 & 0.005536 & 0.037331 \\
\hline m.a.p.e. & 9.213914 & 6.978623 & 7.954685 & 6.397851 & 16.62604 & 2.044886 & 3.584264 & 4.899595 & 2.405671 \\
\hline
\end{tabular}

Примечание. Составлено авторами.
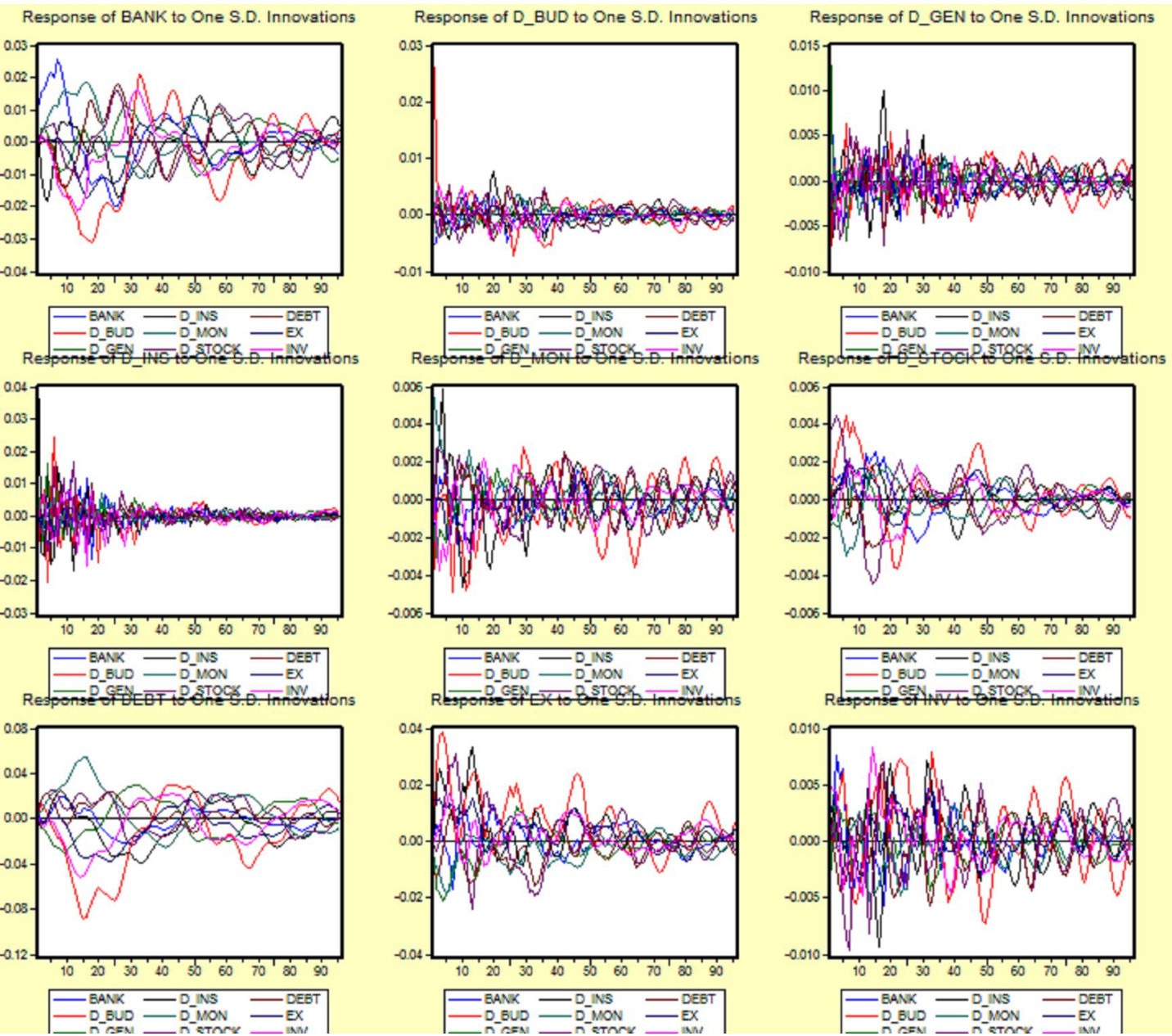

Рис. 4. Функции импульсных откликов интегральных показателей финансовой безопасности стран ЕС 


\section{МЕЖДУНАРОДНЫЕ ИНТЕГРАЦИОННЫЕ ПРОЦЕССЫ}

Анализ данных позволяет сделать вывод, что система является динамически стабильной. В среднесрочной перспективе влияние «шоков» устраняется. Вместе с тем высока вероятность возникновения краткосрочных локальных кризисов, так как реакция в момент воздействия «шока» зачастую имеет характер «взрывных» колебаний.

Результаты декомпозиции дисперсий индикатора уровня финансовой безопасности стран ЕС представлены в таблице 4.

Как видно из таблицы 4, наиболее сильное влияние системные риски оказывают на фондовую, бюджетную и банковскую безопасность.

Аналогично проведен анализ декомпозиции дисперсий прогноза интегральных показателей уровня развития отдельных подсистем финансовой безопасности ЕС. По результатам анализа следует отметить первоочередную значимость угроз безопасности фондового рынка как канала передачи внешних финансовых стрессов / заражений. Об этом говорит число разбалансированных сфер финан- совой безопасности после воздействия локальных «шоков» фондовой безопасности. Для сравнения на рисунке 5 проводится анализ реакций компонент системы финансовой безопасности стран ЕС после воздействия единичного «шока» подсистем долговой и фондовой безопасности в краткосрочном периоде.

Как показано на рисунке 5, воздействие «шока» долговой безопасности в среднесрочной перспективе сводится к 0, система возвращается в состояние равновесия. Воздействие «шока» фондовой безопасности приводит к длительным негативным реакциям в подсистемах монетарной, долговой, валютной безопасности.

Для оценки значимости влияния финансовых и реальных каналов финансовых стрессов / заражений осуществлено оценивание модели с учетом интегрального показателя уровня развития мировой экономики (WORD). Последний является синтетической, равнодействующей величиной такой системы индикторов развития мировой экономики, как индекс мировых цен на нефть (Oil_Price), ставка про-

Таблица 4

Декомпозиция дисперсий, вызванная «шоками» валютной безопасности

\begin{tabular}{|c|c|c|c|c|c|c|c|c|c|}
\hline Period & BANK & D_BUD & D_GEN & D_INS & D_MON & D_STOCK & DEBT & EX & INV \\
\hline 1 & 15.75420 & 20.14096 & 64.10484 & 0.000000 & 0.000000 & 0.000000 & 0.000000 & 0.000000 & 0.000000 \\
\hline 2 & 14.68204 & 14.67344 & 48.35125 & 10.35439 & 0.587126 & 8.428124 & 1.603323 & 1.163935 & 0.156372 \\
\hline 3 & 14.37008 & 13.64324 & 45.00133 & 11.73439 & 0.763383 & 9.411005 & 2.583172 & 1.140748 & 1.352648 \\
\hline 4 & 12.22389 & 12.81852 & 38.32230 & 9.974157 & 0.688880 & 16.51599 & 2.848857 & 1.282294 & 5.325111 \\
\hline 5 & 15.55598 & 11.22926 & 33.19222 & 10.72575 & 0.790311 & 19.86456 & 2.886331 & 1.144127 & 4.611462 \\
\hline 6 & 15.06153 & 15.20737 & 34.03330 & 9.938398 & 0.947852 & 17.22434 & 2.403591 & 1.082744 & 4.100879 \\
\hline 7 & 14.37183 & 16.17358 & 31.21287 & 9.813323 & 0.892613 & 20.16959 & 2.195509 & 1.153355 & 4.017323 \\
\hline 8 & 14.02358 & 15.92323 & 31.21380 & 9.625286 & 0.974095 & 20.72972 & 2.402887 & 1.176257 & 3.931146 \\
\hline 9 & 13.19090 & 14.85956 & 29.30281 & 9.529823 & 1.040546 & 22.24481 & 4.261391 & 1.409595 & 4.160570 \\
\hline 10 & 12.60311 & 14.39461 & 28.36878 & 9.388484 & 2.645746 & 22.36338 & 4.869070 & 1.391337 & 3.975477 \\
\hline 11 & 12.77631 & 13.89036 & 28.10428 & 9.291252 & 2.936460 & 21.56388 & 4.949192 & 1.348415 & 5.139843 \\
\hline 12 & 12.41536 & 13.02916 & 25.98465 & 8.717034 & 4.351362 & 21.82923 & 4.723856 & 2.762469 & 6.186883 \\
\hline
\end{tabular}

Примечание. Составлено авторами.
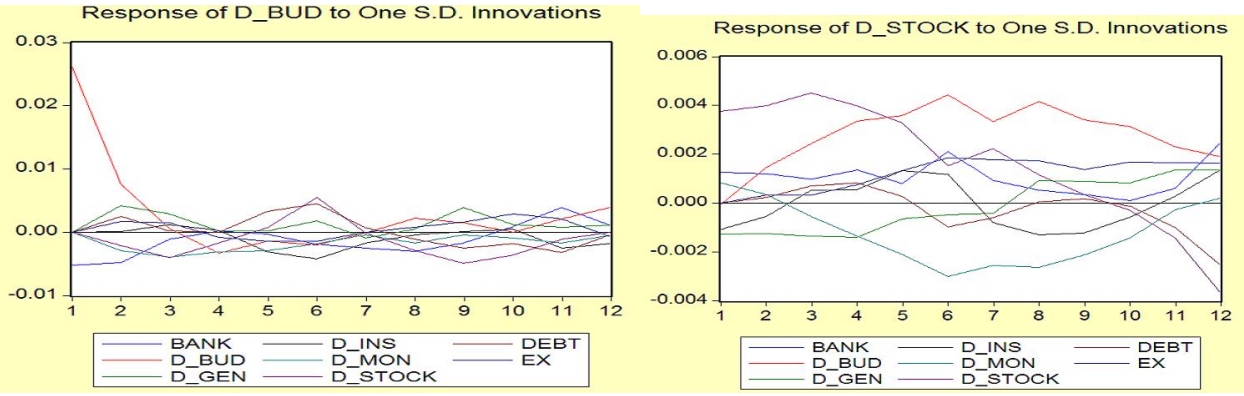

Рис. 5. Функции импульсных откликов вследвие воздействия «шоков» долговой и фондовой безопасности 
Анализ динамических эффектов влияния «шоков» на экономическую безопасность макрорегионов

цента в США (Int_Rate), темп прироста ВВП стран - партнеров EC (GDP). Результаты оценивания модели даны в таблице 5 .

Как видно из таблицы 5, финансовая система стран Евросоюза не подвержена су- щественному влиянию внешних угроз. Функция импульсных откликов на «шоки» каждой из приведенных выше переменных уровня развития мировой экономики приведена на рисунке 6 .

Таблица 5

Результаты оценивания модели с учетом интегрального показателя уровня развития мировой экономики

\begin{tabular}{|c|c|c|c|c|c|c|c|c|c|}
\hline \multicolumn{10}{|c|}{ Vector Autoregression Estimates } \\
\hline \multicolumn{10}{|c|}{ Included observations: 88 after adjustments } \\
\hline \multicolumn{10}{|c|}{ Standard errors in ( ) \& t-statistics in [ ] } \\
\hline & BANK & D_BUD & D_GEN & D_INS & D_MON & D_STOCK & DEBT & EX & INV \\
\hline \multirow[t]{3}{*}{ WORD } & -0.028531 & -0.015088 & 0.013862 & 0.322200 & -0.005966 & 0.016572 & -0.048660 & 0.078998 & 0.039143 \\
\hline & $(0.06786)$ & $(0.15046)$ & $(0.08996)$ & $(0.20098)$ & $(0.03965)$ & $(0.02457)$ & $(0.10229)$ & $(0.13253)$ & $(0.03708)$ \\
\hline & {$[-0.42042]$} & {$[-0.10028]$} & {$[0.15409]$} & {$[1.60311]$} & {$[-0.15046]$} & {$[0.67435]$} & {$[-0.47572]$} & {$[0.59607]$} & {$[1.05568]$} \\
\hline R-squared & 0.995769 & 0.721486 & 0.912913 & 0.910204 & 0.941007 & 0.977348 & 0.994361 & 0.988009 & 0.985949 \\
\hline Sum sq. resids & 0.012664 & 0.062253 & 0.022253 & 0.111077 & 0.004324 & 0.001661 & 0.028771 & 0.048299 & 0.003780 \\
\hline S.E. equation & 0.023465 & 0.052025 & 0.031105 & 0.069494 & 0.013711 & 0.008497 & 0.035368 & 0.045825 & 0.012821 \\
\hline F-statistic & 84.57467 & 0.930955 & 3.767251 & 3.642772 & 5.732494 & 15.50579 & 63.37512 & 29.61062 & 25.21753 \\
\hline Log likelihood & 264.3730 & 194.3044 & 239.5678 & 168.8278 & 311.6553 & 353.7610 & 228.2660 & 205.4713 & 317.5646 \\
\hline Akaike AIC & -4.531204 & -2.938737 & -3.967450 & -2.359723 & -5.605802 & -6.562750 & -3.710590 & -3.192530 & -5.740104 \\
\hline Schwarz SC & -2.701353 & -1.108886 & -2.137599 & -0.529872 & -3.775951 & -4.732899 & -1.880739 & -1.362679 & -3.910253 \\
\hline
\end{tabular}

Примечание. Составлено авторами.

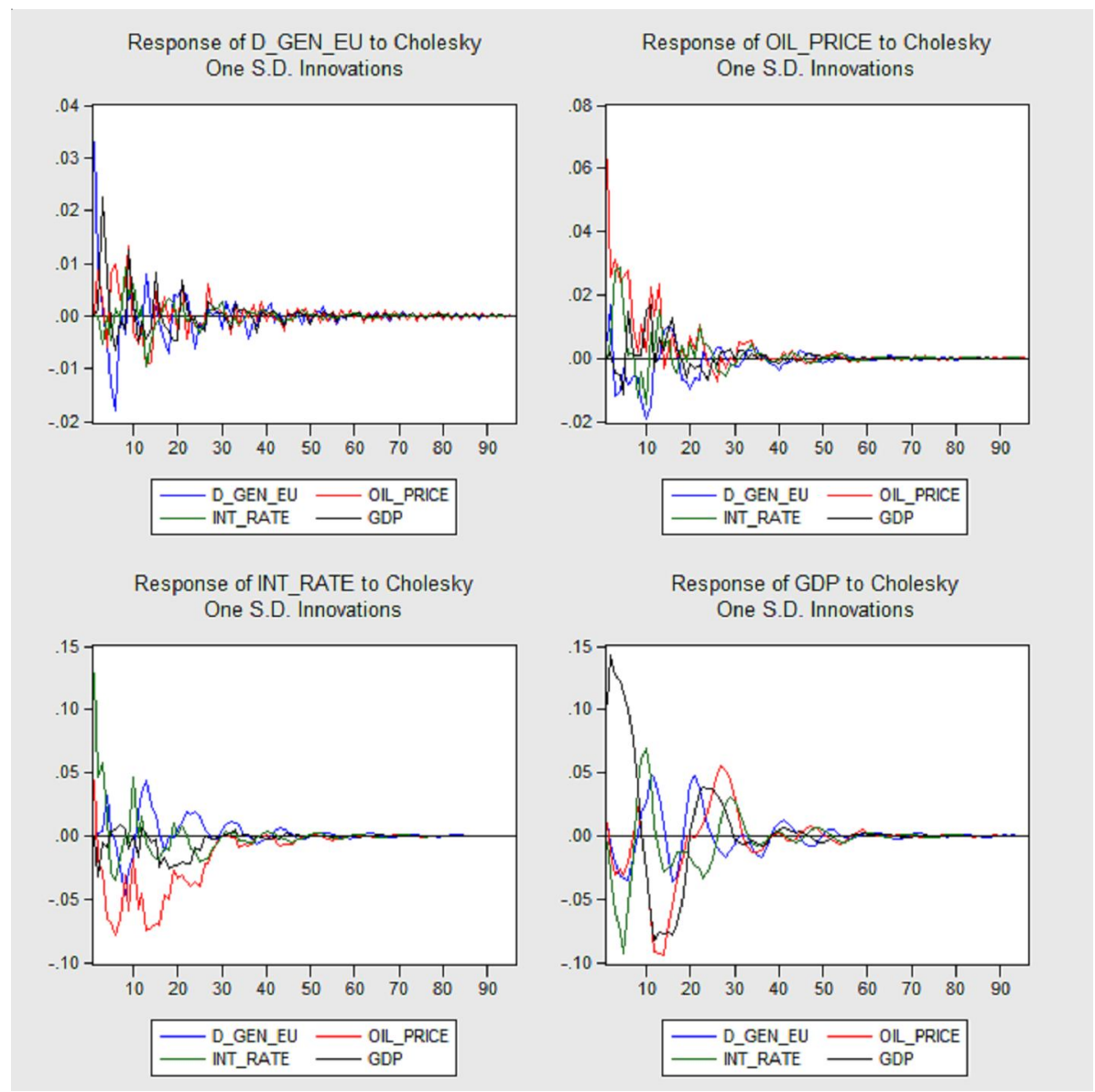

Рис. 6. Функция импульсных откликов уровня финансовой безопасности ЕС на «внешние шоки» 


\section{МЕЖДУНАРОДНЫЕ ИНТЕГРАЦИОННЫЕ ПРОЦЕССЫ}

Функции импульсных откликов (рис. 6) показывают, что последствия внешних «шоков» незначительны с точки зрения числа разбалансированных сфер финансовой безопасности ЕС. В среднесрочной перспективе последствия воздействия «внешних шоков» сводятся к 0 . Страны ЕС имеют стабильно работающую, жизнеобеспечивающую финансовую систему. Вместе с этим следует отметить высокую вероятность локальных кризисов в отдельных подсистемах финансовой безопасности. Так, в краткосрочном периоде наблюдаются значимые по глубине отрицательные флуктуации.

Аналогичный анализ был проведен для динамически нестабильных систем на примере Украины. Для описания динамики индикаторов финансовой безопасности выбрана модель VAR (8). Значения информационного критерия Акайка, который применялся для обоснования величины лага в модели, приведены в таблице 6 .

Критерии качества уравнений, вошедших в модель VAR (8), даны в таблице 7.

Анализ данных, приведенных в таблице 7, позволяет сделать вывод, что значение коэффициента детерминации составляет от 0.746216 до 0.956088 , что говорит о статистической значи- мости модели. Значение средней абсолютной процентной ошибки аппроксимации, которая варьируется в диапазоне от 1,81 \% до 16,91 \%, свидетельствует о хорошей точности прогноза.

Результаты анализа функции импульсных откликов приведены на рисунке 7.

Анализ данных, приведенных на рисунке 7, позволяет сделать вывод, что система не является динамически стабильной и через пять лет будет находиться в точке бифуркации (рис. 7a). Нейтрализация угроз валютной безопасности (рис. 7б) позволит стабилизировать ситуацию.

Результаты декомпозиции дисперсий, показывающие пропорции дисперсии, вызванные «шоками», оказывающими влияние на динамику валютной безопасности, приведены в таблице 8.

Как видно из таблицы 8, «шоки» валютной безопасности оказывают существенное дестабилизирующее влияние практически на все подсистемы, и прежде всего долговую безопасность, безопасность банковской системы, инвестиционную безопасность, которые в дальнейшем сами генерируют дополнительные риски для валютной безопасности.

Таблица 6

Значения информационного критерия Акайка

\begin{tabular}{|c|c|c|}
\hline $\begin{array}{c}\text { Лаг, который } \\
\text { учитывался в модели }\end{array}$ & $\begin{array}{c}\text { Количество значимых } \\
\text { причинно-следственных связей }\end{array}$ & $\begin{array}{c}\text { Критерий } \\
\text { Акайка }\end{array}$ \\
\hline 1 & 11 & $-34,05073$ \\
\hline 2 & 13 & $-33,69284$ \\
\hline 3 & 13 & $-33,18763$ \\
\hline 4 & 9 & $-32,67463$ \\
\hline 5 & 10 & $-32,64069$ \\
\hline 6 & 6 & $-33,26883$ \\
\hline 7 & 7 & $-36,16740$ \\
\hline $\mathbf{8}$ & $\mathbf{1 3}$ & $\mathbf{- 4 2 , 1 4 8 8 1}$ \\
\hline
\end{tabular}

Примечание. Составлено авторами.

Критерии качества уравнений VAR-модели $(p=8)$

\begin{tabular}{|l|c|c|c|c|c|c|c|c|c|}
\hline $\begin{array}{c}\text { Условное } \\
\text { обозначение }\end{array}$ & BANK_U & BUD_U & D_DEBT_U & D_EX_U & GEN_U & INV_U & INS_U & MON_U & STOCK_U \\
\hline R-squared & 0.950121 & 0.948928 & 0.746216 & 0.781568 & 0.925050 & 0.928446 & 0.914246 & 0.956088 & 0.853226 \\
\hline Sum sq. resids & 0.086687 & 0.024622 & 0.101433 & 0.042658 & 0.005739 & 0.045079 & 0.024256 & 0.068872 & 0.000679 \\
\hline S.E. equation & 0.078689 & 0.041937 & 0.085119 & 0.055200 & 0.020247 & 0.056745 & 0.041624 & 0.070139 & 0.006964 \\
\hline Akaike AIC & -2.395323 & -3.653974 & -2.238224 & -3.104411 & -5.110349 & -3.049199 & -3.668957 & -2.625370 & -7.244676 \\
\hline Schwarz SC & -0.326227 & -1.584879 & -0.169129 & -1.035315 & -3.041254 & -0.980104 & -1.599861 & -0.556275 & -5.175581 \\
\hline m.p.e. & 0.093739 & 0.079472626 & 0.095459 & 0.069527 & 0.017049 & 0.058969 & 0.035803 & 0.092923 & 0.00654 \\
\hline m.a.p.e. & 3.231947 & 13.07096 & 12.94245 & 9.784692 & 14.73106 & 15.23299 & 16.91419 & 14.64215 & 1.814057 \\
\hline
\end{tabular}


Анализ динамических эффектов влияния «шоков» на экономическую безопасность макрорегионов
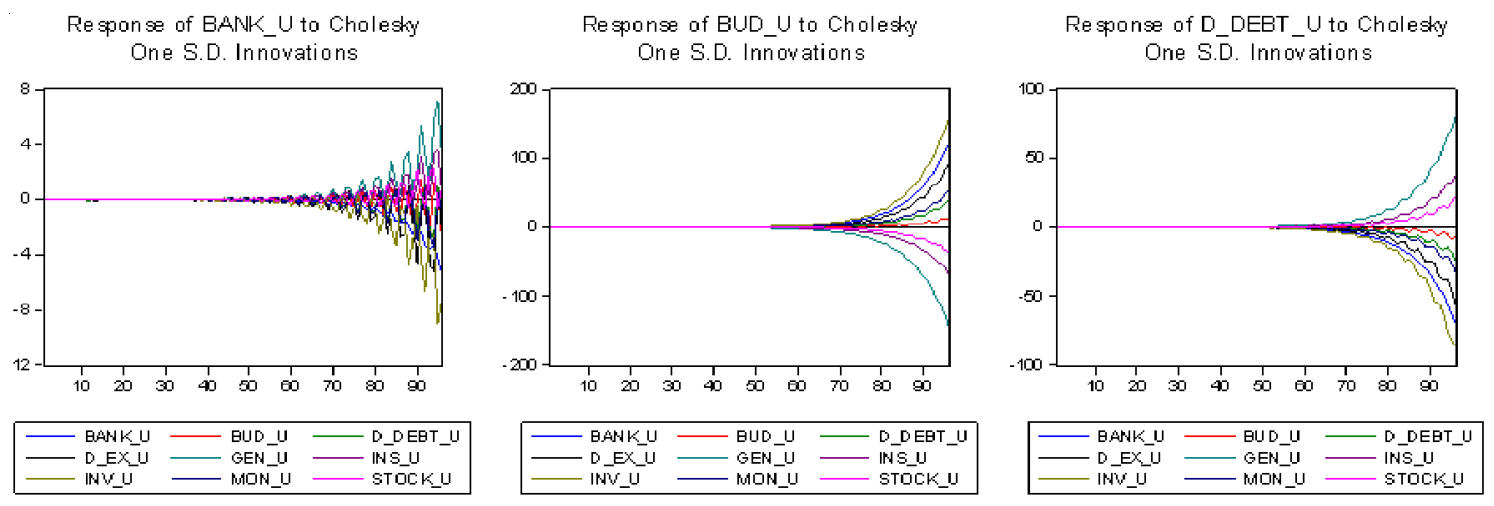

а) с учетом индикаторов валютной безопасности
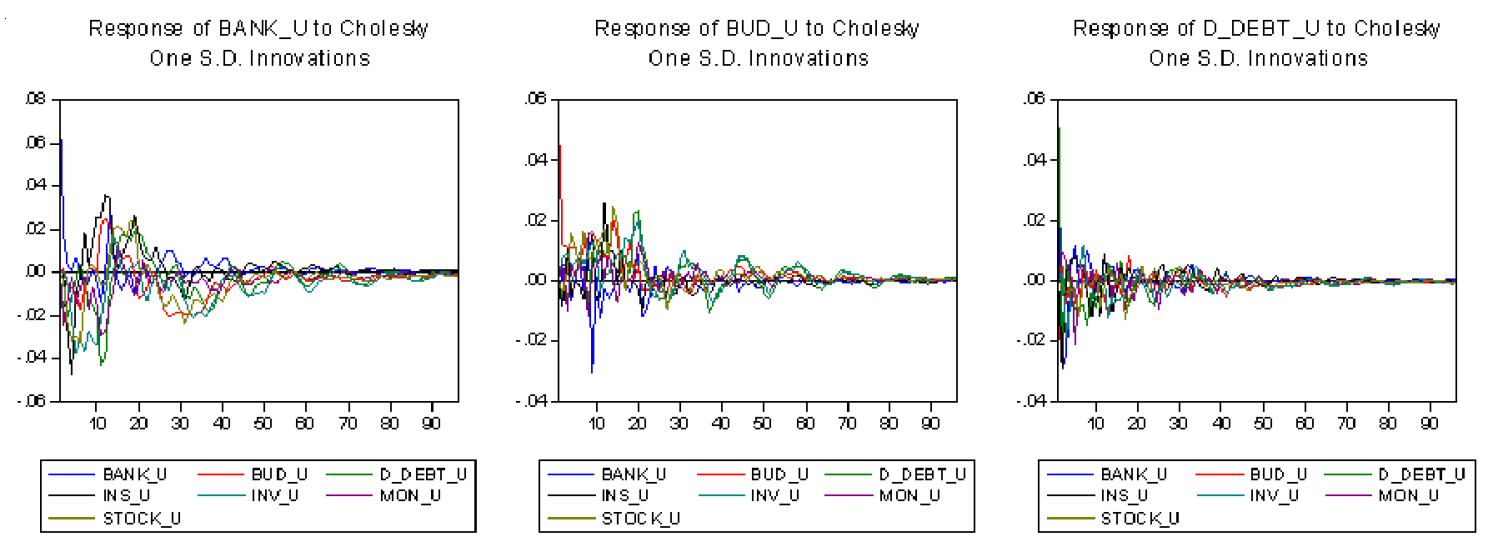

Response of ING_U to Cholesw one S.D. Innowations
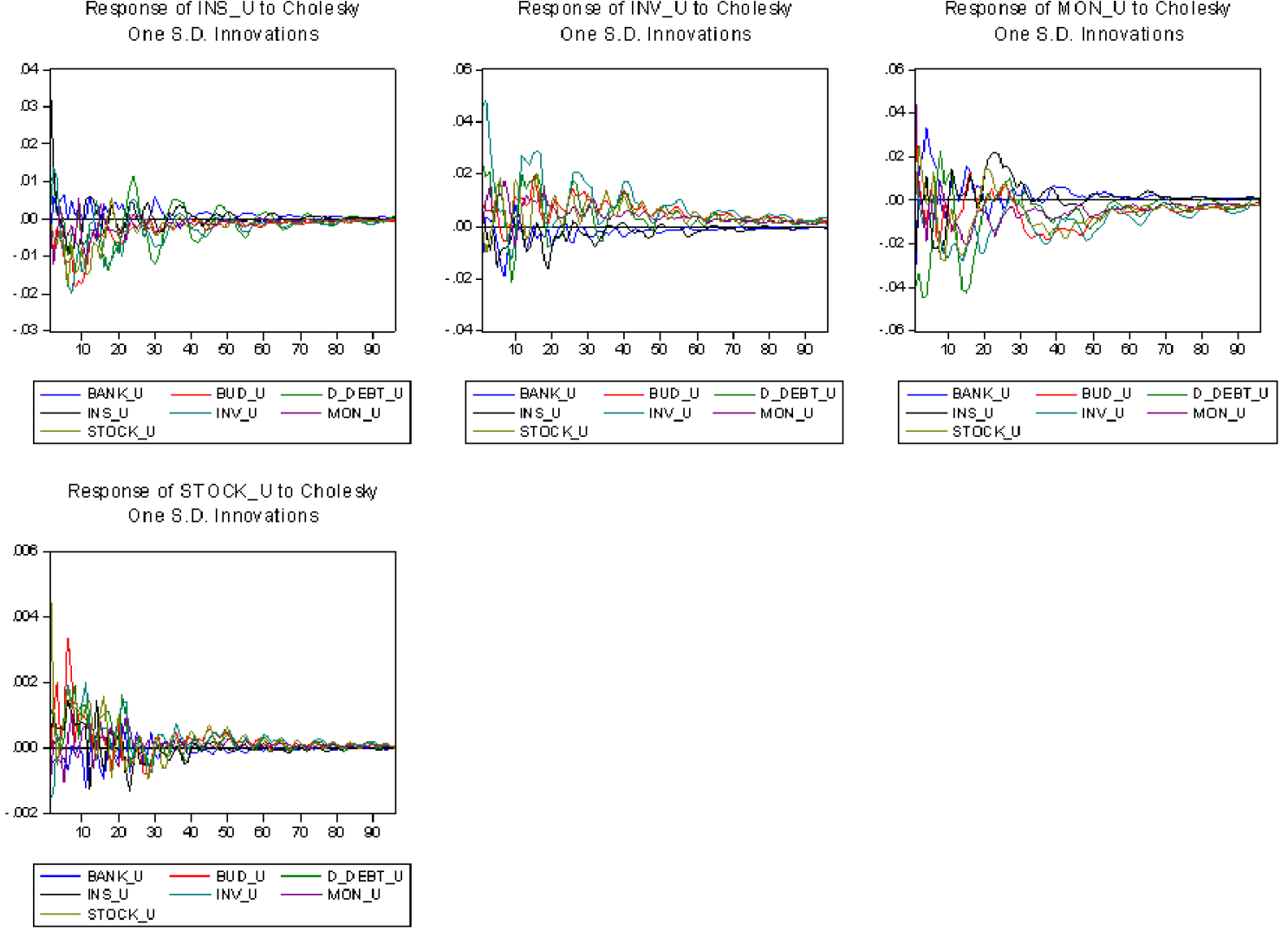

б) без учета индикаторов валютной безопасности

Рис. 7. Функции импульсных откликов (фрагмент) 
Декомпозиция дисперсий, вызванная «шоками» валютной безопасности

\begin{tabular}{|c|c|c|c|c|c|c|c|c|c|}
\hline Period & BANK_U & BUD_U & D_DEBT_U & D_EX_U & GEN_U & INS_U & INV_U & MON_U & STOCK_U \\
\hline 1 & 15.18119 & 1.260403 & 57.39022 & 26.16818 & 0.000000 & 0.000000 & 0.000000 & 0.000000 & 0.000000 \\
\hline 2 & 13.19598 & 2.028122 & 48.62171 & 26.36987 & 2.651754 & 6.239155 & 0.023729 & 0.306103 & 0.563581 \\
\hline 3 & 20.51773 & 5.760387 & 37.91166 & 22.46248 & 2.001071 & 4.742999 & 3.726343 & 2.440478 & 0.436847 \\
\hline 4 & 17.35468 & 5.432773 & 34.84492 & 20.63810 & 5.416511 & 4.015034 & 9.069995 & 2.411938 & 0.816052 \\
\hline 5 & 15.64125 & 6.052333 & 31.67280 & 20.56667 & 5.319157 & 7.264278 & 8.815500 & 2.199206 & 2.468806 \\
\hline 6 & 18.29877 & 7.010413 & 28.60915 & 19.10096 & 4.782502 & 7.010360 & 10.47629 & 2.479982 & 2.231580 \\
\hline 7 & 19.11796 & 6.123121 & 25.34664 & 20.26249 & 4.681273 & 8.245786 & 11.39368 & 2.557175 & 2.271866 \\
\hline 8 & 17.24428 & 6.312037 & 23.49581 & 20.46338 & 7.193273 & 8.200384 & 11.40751 & 2.882305 & 2.801016 \\
\hline 9 & 15.72249 & 5.764912 & 22.39390 & 24.41215 & 6.774315 & 7.694852 & 10.76029 & 3.303664 & 3.173415 \\
\hline 10 & 14.84183 & 6.160437 & 21.25736 & 23.16962 & 10.75693 & 7.564557 & 10.18114 & 3.093132 & 2.975000 \\
\hline 11 & 14.01960 & 6.066624 & 19.41079 & 21.09419 & 10.85685 & 7.173799 & 15.18436 & 3.137743 & 3.056049 \\
\hline 12 & 16.38136 & 5.921841 & 18.84017 & 20.47358 & 10.78200 & 7.218553 & 14.05763 & 3.078108 & 3.246764 \\
\hline
\end{tabular}

На завершающем этапе исследования в VAR-модель динамики индикаторов финансовой безопасности Украины в качестве экзогенной переменной был включен показатель уровня финансовой безопасности стран Еврозоны (GEN_EU). Результаты оценивания приведены в таблице 9.

Данные таблицы 9 позволяют сделать вывод, что изменение уровня финансовой безопасности стран Евросоюза оказывает достаточно сильное влияние на динамику подсистем финансовой безопасности Украины, и прежде всего подсистем валютной безопас- ности, безопасности денежного рынка, долговой безопасности.

Результаты оценивания VAR-модели динамики индикаторов финансовой безопасности Украины с учетом экзогенной переменной состояния реального сектора экономики (REAL) приведены в таблице 10.

Анализ данных позволяет сделать вывод, что по результатам оценивания состояние реального сектора экономики на текущий момент времени не оказывает доминантного влияния на усиление глубины кризиса в финансовой системе.

Результаты оценивания модели (фрагмент)

Таблича 9

\begin{tabular}{|l|c|c|c|c|c|c|c|c|}
\hline $\begin{array}{c}\text { Условное } \\
\text { обозначение }\end{array}$ & BANK_U & BUD_U & D_DEBT_U & D_EX_U & INS_U & INV_U & MON_U & STOCK_U \\
\hline Параметры модели & & & & & & & & \\
\hline D_GEN_EU & -0.169461 & 0.231499 & -0.964688 & 0.640389 & -0.088633 & -0.381518 & 0.821458 & -0.029895 \\
\hline $\begin{array}{l}\text { Cтандартное от- } \\
\text { клонение }\end{array}$ & $(0.45585)$ & $(0.23564)$ & $(0.41731)$ & $(0.26795)$ & $(0.24116)$ & $(0.31307)$ & $(0.33903)$ & $(0.03970)$ \\
\hline t-критерий & {$[-0.37175]$} & {$[0.98241]$} & {$[-2.31168]$} & {$[\mathbf{2 . 3 8 9 9 4}]$} & {$[-0.36753]$} & {$[-1.21863]$} & {$[\mathbf{2 . 4 2 2 9 3 3}$} & {$[-0.75295]$} \\
\hline Критерии качества & & & & & & & & \\
\hline R-squared & 0.950646 & 0.952457 & 0.820148 & 0.848245 & 0.915127 & 0.935782 & 0.969749 & 0.859359 \\
\hline Akaike AIC & -2.382909 & -3.702600 & -2.559582 & -3.445629 & -3.656305 & -3.134378 & -2.975038 & -7.264374 \\
\hline Schwarz SC & -0.285470 & -1.605161 & -0.462142 & -1.348190 & -1.558866 & -1.036939 & -0.877599 & -5.166935 \\
\hline
\end{tabular}

Результаты оценивания модели (фрагмент)

\begin{tabular}{|l|c|c|c|c|c|c|c|c|c|}
\hline $\begin{array}{c}\text { Условное } \\
\text { обозначение }\end{array}$ & BANK_U & BUD_U & D_DEBT_U & D_EX_U & GEN_U & INS_U & INV_U & MON_U & STOCK_U \\
\hline Параметры модели & & & & & & & & & \\
\hline D_REAL & -0.041731 & 0.012840 & -0.131728 & 0.058119 & 0.002127 & 0.009294 & -0.052698 & 0.089647 & -0.001124 \\
\hline $\begin{array}{l}\text { Стандартное от- } \\
\text { клонение }\end{array}$ & $(0.07238)$ & $(0.03890)$ & $(0.07037)$ & $(0.04883)$ & $(0.01885)$ & $(0.03869)$ & $(0.05080)$ & $(0.06042)$ & $(0.00648)$ \\
\hline t-критерий & {$[-0.57655]$} & {$[0.33006]$} & {$[-1.87189]$} & {$[1.19027]$} & {$[0.11283]$} & {$[0.24024]$} & {$[-1.03740]$} & {$[1.48372]$} & {$[-0.17346]$} \\
\hline Критерии качества & & & & & & & & & \\
\hline R-squared & 0.951365 & 0.949352 & 0.800097 & 0.803034 & 0.925123 & 0.914625 & 0.933917 & 0.962447 & 0.853565 \\
\hline Akaike AIC & -2.397583 & -3.639331 & -2.453889 & -3.184863 & -5.088340 & -3.650398 & -3.105747 & -2.758821 & -7.223999 \\
\hline Schwarz SC & -0.300144 & -1.541892 & -0.356449 & -1.087424 & -2.990901 & -1.552959 & -1.008307 & -0.661382 & -5.126560 \\
\hline
\end{tabular}




\section{Заключение}

Таким образом, разработаны модели анализа индикаторов финансовой безопасности динамически стабильных систем, которые показали, что в современных условиях высока вероятность формирования краткосрочных локальных кризисов, так как реакция в момент воздействия «шока» зачастую имеет характер «взрывных» колебаний. Исследование моделей динамически нестабильной системы позволило определить точки бифуркации, доминантные угрозы, устранение которых дает возможность стабилизировать ситуацию. Выявлены подсистемы безопасности, которые наиболее чувствительны к влиянию внешних «шоков», первоочередные по значимости каналы передачи внешних стрессов / заражений. Разработанный комплекс моделей может рассматриваться как элемент модельного базиса прогнозно-аналитического механизма СЭБР.

\section{СПИСОК ЛИТЕРАТУРЫ}

1. Адаптивные методы в системах принятия решений : монография / под ред. Н. А. Кизима, Т. С. Клебановой. - Х. : ИНЖЭК, 2007. - 368 с.

2. Великоіваненко, Г. І. Ієрархічна логіколінгвістична модель оцінювання інвестиційного потенціалу України з урахуванням ризику / Г. І. Великоіваненко, I. В. Мірошниченко // Культура народов Причерноморья. - 2012. - № 231. - С. 14-18.

3. Гурьянова, Л. С. Методы выбора диагностических показателей финансовой безопасности / Л. С. Гурьянова, В. В. Непомнящий // Бизнес-Информ. - 2013. - № 4. - С. 377-381.

4. Гурьянова, Л. С. Модели прогнозирования в системе стратегического управления финансовой деятельностью предприятия / Л. С. Гурьянова, С. В. Прокопович, Т. Н. Трунова // Прикладні аспекти прогнозування розвитку складних соціально-економічних систем : монографія / за ред. О. І. Черняка, П. В. Захарченка. - Бердянськ : Видавець Ткачук О.В., 2015. C. $50-64$.

5. Гур'янова, Л. С. Моделювання збалансованого соціально-економічного розвитку регіонів: монографія / Л. С. Гур'янова. - Бердянськ : ФОП Ткачук О.В., 2013. - 406 с.

6. Маринчук, С. Г. Моделювання стратегій використання офшорних зон для податкової оптимізації суб'єктами господарювання : автореф. дис. канд. екон. наук / М. Г. Маринчук. - Черкаси :
Східноєвропейський університет економіки і менеджменту, 2015. - 20 с.

7. Моделювання економічної безпеки: держава, регіон, підприємство: монографія / Геєць В. М., Кизим М. О., Клебанова Т. С., Черняк О. І. та ін.; За ред. Гейця В. М. - Х. : ІНЖЕК, 2006. - 240 с.

8. Нелинейные методы прогнозирования экономической динамики региона / Р. М. Нижегородцев, Е. Н. Грибова, Л. П. Зенькова, А. Ю. Хатько. Харьков : Инжэк, 2008. - 320 с.

9. Чаговец, Л. А. Моделирование производственно-фискальных эффектов в системе экономической безопасности государства / Л. А. Чаговец // Бизнес-Информ. - 2013. - № 10. - С. 130-135.

10. Черняк, О. І. Криза платіжного балансу: фактори, індикатори та способи попередження / О. І. Черняк, В. Р. Хом'як // Економіка і прогнозування. - 2011. - № 4. - С. 27-37.

\section{REFERENCES}

1. Kizim N.A., Klebanova T.S., eds. Adaptivnye metody $v$ sistemakh prinyatiya resheniy: monografiya [Adaptive Methods in Decision-Making Systems: Monograph]. Kharkiv, INJEK Publ., 2007. 368 p.

2. Velykoivanenko G.I., Miroshnichenko I.B. Ierarkhichna logiko-lingvistichna model otsinyuvannya investitsiynogo potentsialu Ukraïni z urakhuvannyam riziku [The Hierarchical Logical and Linguistic Model for Assessment of Ukraine's Investment Potential with Regard to Risk]. Kultura narodov Prichernomorya [Culture ofBlack Sea Nations], 2012, no. 231, pp. 14-18.

3. Guryanova L.S., Nepomnyashchiy V.V. Metody vybora diagnosticheskikh pokazateley finansovoy bezopasnosti [Methods of Choosing Diagnostic Indicators of Financial Security]. BiznesInform, 2013, no. 4, pp. 377-381.

4. Guryanova L.S., Prokopovich S.V., Trunova T.N. Modeli prognozirovaniya $\mathrm{v}$ sisteme strategicheskogo upravleniya finansovoy deyatelnostyu predpriyatiya [Models of Forecasting in the System of an Enterprise Financial Activity Strategic Management]. ChernyakA.I., ZakharchenkoP.V., eds. Prikladni aspekti prognozuvannya rozvitku skladnikh sotsialno-ekonomichnikh sistem: monografiya [Applied Aspects of Forecasting Complex Socio-Economic Systems. Monograph]. Berdyansk, Vidavets'TkachukO.V., 2015,pp. 50-64.

5. Guryanova L.S. Modelyuvannya zbalansovanogo sotsialno-ekonomichnogo rozvitku regioniv: monografiya [Modeling of Balanced Socio-Economic Development of Regions: Monograph]. Berdyansk, Vidavets'Tkachuk O.V., 2013. 406 p.

6. Marinchuk S.G. Modelyuvannya strategiy vikoristannya ofshornikh zon dlya podatkovoï 


\section{МЕЖДУНАРОДНЫЕ ИНТЕГРАЦИОННЫЕ ПРОЦЕССЫ}

optimizatsiï subcktami gospodaryuvannya: avtoref. dis. kand. ekon. nauk [Modeling of Strategies for Using Offshore Areas for Enterprise Tax Optimization. Cand. econ. sci. abs. diss.]. Cherkasi, Skhidno€vropeyskiy universitet ekonomiki i menedzhmentu, 2015.20 p.

7. Geets V.M., Kizim M.O., Klebanova T.S., Chernyak O.I., et al. Modelyuvannya ekonomichnoï bezpeki: derzhava, region, pidpricmstvo: monografiya [Economic Security Modeling: State, Region, Enterprise]. Kharkiv, INJEK Publ., 2006. 240 p.

8. Nizhegorodtsev R.M., Gribova E.N., Zenkova L.P., Khatko A.Yu. Nelineynye metody prognozirovaniya ekonomicheskoy dinamiki regiona
[Nonlinear Methods for Forecasting the Region Economic Dynamics]. Kharkiv, INJEK Publ., 2008. 320 p.

9. Chagovets L.A. Modelirovanie proizvodstvenno-fiskalnykh effektov v sisteme ekonomicheskoy bezopasnosti gosudarstva [Modeling of Production-Fiscal Effects in the System of Economic Security of the State]. Biznes-Inform, 2013, no. 10 , pp. 130-135.

10. Chernyak O.I., Homyak V.R. Kriza platizhnogo balansu: faktori, indikatori ta sposobi poperedzhennya [Payments Balance Crisis: Factors, Indicators and Ways of Prevention]. Ekonomika i prognozuvannya, 2011, no. 4, pp. 27-37.

\section{Information about the Authors}

Lidiya S. Guryanova, Doctor of Sciences (Economics), Associate Professor, Professor of Department of Economic Cybernetics, Simon Kuznets Kharkiv National University of Economics, Prosp. Nauki, 9-a, 61166 Kharkiv, Ukraine, guryanovalidiya@gmail.com.

Tamara S. Klebanova, Doctor of Sciences (Economics), Professor, Head of Department of Economic Cybernetics, Simon Kuznets Kharkiv National University of Economics, Prosp. Nauki, 9-a, 61166 Kharkiv, Ukraine, t_kleb@ukr.net.

Sergey A. Razumovskiy, Doctor of Sciences (Philosophy), Professor, Simon Kuznets Kharkiv National University of Economics, Director of Metalloshtamp-M ALC, Prosp. Nauki, 9-a, 61166 Kharkiv, Ukraine,rsa3720442@gmail.com.

Vyacheslav V. Nepomnyashchiy, Postgraduate Student, Department of Economic Cybernetics, Simon Kuznets Kharkiv National University of Economics, Prosp. Nauki, 9-a, 61166 Kharkiv, Ukraine, ra_bdm@mail.ru.

\section{Информация об авторах}

Лидия Семеновна Гурьянова, доктор экономических наук, доцент, профессор кафедры экономической кибернетики, Харьковский национальный экономический университет им. С. Кузнеца, просп. Науки, 9-а, 61166 г. Харьков, Украина, guryanovalidiya@gmail.com.

Тамара Семеновна Клебанова, доктор экономических наук, профессор, заведующая кафедрой экономической кибернетики, Харьковский национальный экономический университет им. С. Кузнеца, просп. Науки, 9-a, 61166 г. Харьков, Украина, t_kleb@ukr.net.

Сергей Александрович Разумовский, доктор философских наук, профессор, Харьковский национальный экономический университет им. С. Кузнеца, директор ОДО «Металлоштамп-М», просп. Науки, 9-a, 61166 г. Харьков, Украина, rsa3720442@gmail.com.

Вячеслав Владимирович Непомнящий, аспирант кафедры экономической кибернетики, Харьковский национальный экономический университет им. С. Кузнеца, просп. Науки, 9-а, 61166 г. Харьков, Украина, ra_bdm@mail.ru. 